\title{
Efficiency of Ionic Liquid 1-Ethyl-3-Methyl-Imidazolium Acetate ([EMIM][Ac]) in Enhanced Medium Oil Recovery
}

\author{
Ali Alarbah, Mohamed Shirif, Ezeddin Shirif* \\ Faculty of Engineering, University of Regina, Regina, Canada \\ Email: *ezeddin.shirif@uregina.ca
}

How to cite this paper: Alarbah, A., Shirif, M. and Shirif, E. (2017) Efficiency of Ionic Liquid 1-Ethyl-3-Methyl-Imidazolium Acetate ([EMIM] [Ac]) in Enhanced Medium Oil Recovery. Advances in Chemical Engineering and Science, 7, 291-303.

https://doi.org/10.4236/aces.2017.73022

Received: April 11, 2017

Accepted: July 10, 2017

Published: July 13, 2017

Copyright $\odot 2017$ by authors and Scientific Research Publishing Inc. This work is licensed under the Creative Commons Attribution International License (CC BY 4.0).

http://creativecommons.org/licenses/by/4.0/

(c) (i) Open Access

\begin{abstract}
Chemical flooding is one of the most efficient methods for Enhanced Oil Recovery (EOR). This study demonstrates the efficiency of mixing different concentrations of Ionic Liquid (IL), 1-Ethyl-3-Methyl-Imidazolium Acetate ([EMIM][Ac]), with Weyburn brine to improve a medium oil recovery, Weyburn oil, from an unconsolidated sand pack sample at room conditions. Effects of Slug Size (SS), IL + brine slug initiation time, and combining IL with alkali on the Recovery Factor (RF) were investigated. This study showed that the optimum concentration of ([EMIM][AC]) was $1000 \mathrm{ppm}$ and the most efficient injection time of the chemical slug was at the beginning of the flooding procedure (as secondary flooding mode). In addition, it was proved that the potential of injecting a slug of IL + brine is much better than that of introducing a slug of alkali + brine. Besides, the combination of IL and alkali (AIL) resulted in better RF than injecting either of them alone. Finally, the Surface Tension (SFT), pH, wettability alteration, and viscosity of the displacing phases were measured.
\end{abstract}

\section{Keywords}

[EMIM][Ac], Medium Oil, IL Concentration, Slug Size, Injection Time

\section{Introduction}

It is crucial to increase oil production from existing reservoirs due to the lack of new oil reservoirs discovered around the world as well as the high cost of exploration and reduction in reservoir drive mechanism [1]. Therefore, most researchers focus on studying new enhanced oil recovery (EOR) techniques. Many 
(EOR) techniques had been proven to increase oil recovery after reservoirs had lost their natural energy [2]. Recently, chemical enhanced oil flooding (CEOR) methods have received significant attention to improve oil recovery using surfactants flooding, polymers flooding, alkalis flooding, and alkaline-polymersurfactant flooding [3] [4]. Chemical flooding plays a significant role in reducing interfacial tension, changing the rock wettability and improving the sweeping efficiency by increasing the viscosity and increasing the mobility ratio [5] [6]. However, the application of surfactant flooding is limited due to high toxicity, high cost, low efficiency in harsh environments of high salinity, and adsorption on formation rock which causes formation damage [7]. Due to the increase in oil demand, the necessity of finding new chemicals as alternatives to surfactants is growing.

Today, injecting ionic liquids (IL) has become a pivot application in the oil industry to increase oil recovery. There are many ionic liquid types such as organic salts which have a melting temperature lower than $100^{\circ} \mathrm{C}$ [8]. Additionally, ILs that are used as demulsification to desalt water and salts resulting from crude oil and water emulsions [9]. Compared to other commercial chemicals, ionic liquids have many advantages such as their commercial availability, solvent stability, non-corrosiveness, recyclability, and low toxicity [10]. Many studies presented the extraction of more than $90 \%$ of bitumen from oil sand by using several IL (imidazolium base) mixed with non-polar solvents [11] [12] [13]. Hezave et al. (2013), have reported the effects of using-dodecyl-3-methayl-imidazolium chloride ([DMIM] $[\mathrm{Cl}])$ at different temperature for enhanced oil recovery; they found that ([DMIM][Cl]) was able to reduce dynamic interfacial tension between one of Iranian oils and high salinity formation brine to improve oil recovery [14]. Moreover, increasing ILs concentration in salt water resulted in an increase in oil recovery factor from sandstone and carbonate reservoirs [15]. On the other hand, Tunnish in 2016 reported that IL 1-Ethyl-3-Methyl-Imidazolium Acetate ([EMIM][Ac]) mixed with different synthetic brines was more efficient to extract pelican heavy oil from sand pack column when mixed with low salinity aqueous solution. The results showed that the reduction in interfacial tension between the oil and displacing mixtures was marginal [16]. Moreover, Pereira et al. studied the effect of different ILs brine solutions on oil recovery; the highest recovery was obtained by 1-ethyl-3-methyl-imidazolum tosylate ([ $\left.\left.\mathrm{C}_{2} \mathrm{MIM}\right][\mathrm{OTS}]\right)$ which was able to extract up to $88 \%$ trapped oil after 4 pore volume (PV) IL solution was flooded into core sample [17]. However, selecting IL and its optimum concentration to improve oil recovery depends on reservoir rock types and reservoir fluid properties.

In this research, experimental measurements were used to study the ability of the IL 1-Ethyl-3-Methyl-Imidazolium Acetate ([EMIM][Ac]) to improve medium oil recovery. Different ([EMIM][Ac]) concentrations mixed with formation brine using different slug size were flooded into an unconsolidated sand pack at room conditions in different scenarios. Moreover, the effect of injecting alkali into sand pack was investigated. Also, the effect of IL on SFT, pH, wettabili- 
ty alteration, and displacing phase viscosity were investigated for the ([EMIM] [Ac]) mixtures and their impact on chemical EOR recovery mechanisms.

\section{Experimental Work}

\subsection{Materials}

In this study, 1-Ethyl-3-Methyl-Imidazolium Acetate ([EMIM][Ac]) with purity of 95 wt $\%$ and alkali $\left(\mathrm{Na}_{2} \mathrm{CO}_{3}\right)$ were supplied from Sigma-Aldrich and used without further purification. The chemical structure of the employed IL ([EMIM][Ac]) is shown in Figure 1. The medium oil sample (API $\left.{ }^{\circ} 30.25\right)$ and brine were obtained from Weyburn reservoir formation. The properties of Weyburn oil and brine are presented in Table 1 . The properties of the sand pack are shown in Table 2.
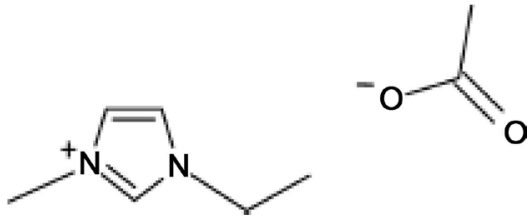

Figure 1. Chemical structure of ([EMIM][Ac]).

Table 1. Properties of brine, oil, and displacing fluids at $21.5^{\circ} \mathrm{C}$.

Brine composition (Fraction)

\begin{tabular}{|c|c|c|c|}
\hline Cations & & Anions & \\
\hline $\mathrm{Na}$ & 0.3379 & $\mathrm{Cl}$ & 0.571 \\
\hline $\mathrm{K}$ & 0.0084 & $\mathrm{Br}$ & \\
\hline $\mathrm{Ca}$ & 0.0259 & I & \\
\hline $\mathrm{Mg}$ & 0.0058 & $\mathrm{HCO}_{3}$ & 0.0091 \\
\hline $\mathrm{Ba}$ & 0 & $\mathrm{SO}_{4}$ & 0.414 \\
\hline $\mathrm{Sr}$ & 0.0006 & $\mathrm{CO}_{3}$ & 0 \\
\hline $\mathrm{Fe}$ & 0 & $\mathrm{OK}$ & 0 \\
\hline $\mathrm{Mn}$ & 0 & $\mathrm{H}_{2} \mathrm{~S}$ & \\
\hline \multirow{9}{*}{ Oil SARA fraction (wt\%) } & Brine $\mu(\mathrm{cP})$ & 1.017 & \\
\hline & Brine $\rho\left(\mathrm{gm} / \mathrm{cm}^{3}\right)$ & 1.06645 & \\
\hline & Oil $\mu(\mathrm{cP})$ & 15.355 & \\
\hline & Oil $\rho\left(\mathrm{gm} / \mathrm{cm}^{3}\right)$ & 0.87481 & \\
\hline & Oil API & 30.25 & \\
\hline & Saturates & 60.3 & \\
\hline & Aromatics & 24.1 & \\
\hline & Resins & 10.5 & \\
\hline & Asphaltenes & 3.15 & \\
\hline \multirow{4}{*}{$\begin{array}{l}\text { Displacing fluid } \\
\text { (IL + Brine })\end{array}$} & $\mathrm{C}_{([\mathrm{EMIM}][\mathrm{Ac}])}$ & $\rho\left(\mathrm{gm} / \mathrm{cm}^{3}\right)$ & $\mu(\mathrm{cP})$ \\
\hline & 1000 ppm & 1.075 & 1.437 \\
\hline & $3000 \mathrm{ppm}$ & 1.081 & 1.597 \\
\hline & 5000 ppm & 1.083 & 1.621 \\
\hline (Alkali + Brine) & $\begin{array}{c}\mathrm{C}_{\left(\mathrm{Na}_{2} \mathrm{CO}_{3}\right)} \\
5000 \mathrm{ppm}\end{array}$ & 1.071 & 1.021 \\
\hline
\end{tabular}


Table 2. Petro physical properties of sand pack samples.

\begin{tabular}{ccccc}
\hline $\mathrm{PV}\left(\mathrm{cm}^{3}\right)$ & $\varnothing(\%)$ & $\mathrm{K}($ Darcy $)$ & $\mathrm{S}_{\mathrm{wi}}(\%)$ & $\mathrm{S}_{\mathrm{oi}}(\%)$ \\
\hline $98.5( \pm 2)$ & $41( \pm 2)$ & $5.2( \pm 0.5)$ & $17( \pm 1)$ & $83( \pm 1)$ \\
\hline
\end{tabular}

\subsection{Measurements}

The selected IL ([EMIM][Ac]) for this study was combined at different concentrations with Weyburn brine. The following steps were taken before the flooding process:

1) Prepare the IL mixtures by adding the following amount of ([EMIM][Ac]), (1000 ppm, $3000 \mathrm{ppm}$, and $5000 \mathrm{ppm}$ ), to the brine, the solution is placed on a stirrer (Cole-Parmer Stable Temp Ceramic Stirring Hot Plate) at $120 \mathrm{rpm}$ for 30 - 45 mints.

2) The viscosity of Weyburn oil $(15.355 \mathrm{cP})$, Weyburn brine $(1.07 \mathrm{cP})$, and displacing solutions was measured by using an A Brookfield DV-II viscometer.

3) An Anton Paar DSA $5000 \mathrm{M}$ instrument was used to measure the densities of the aqueous solutions.

4) KRUSS K100 device was used to measure the surface tension of the displacing mixtures using Wilhelmy plate method. Clean the sample vessel and the plate by acetone first and then by clean water before every measurement. Also, the lower edge of the plate is placed straight and parallel to surface of the liquids.

5) The $\mathrm{pH}$ of the displacing phases was measured by a Navi pH Meter. An average value was calculated after every third measurement.

\subsection{Sand Pack Preparation}

A sand pack column with a bulk volume of $235.7 \mathrm{~cm}^{3}$ was packed with dry Ottawa sand to prepare an unconsolidated sand pack. The average size of the sand, 40 - 80 mesh, was measured using sieving analysis. The PV, porosity, absolute permeability, and fluid saturations were measured and listed in Table 2.

\subsection{Flooding Procedure}

A vertically oriented core holder, with a length of $18.75 \mathrm{~cm}$ and an inside diameter of $4 \mathrm{~cm}$, was packed with dry unconsolidated sand. After packing the sand and fixing the caps, the sand pack sample was $100 \%$ vacuumed using a pump until no air bubble came out and then saturated by Weyburn brine to obtain the porosity from the difference between the dry and saturated weight divided by brine density and bulk volume. The column was injected by brine at different injection rates to determine the absolute permeability using Darcy's Law. After taking the petrophysical properties, the core holder was connected to the core flooding system, a conventional core flooding system, vertically and then the sand pack samples was flooded by the medium oil at a rate of $1 \mathrm{cc} / \mathrm{min}$ until no water drop came out from core holder outlet. Total displaced brine represents the original oil in place while the remaining represents the irreducible 
water saturation. In the next stage, the injection rate was held at a constant rate of $2 \mathrm{cc} / \mathrm{min}$, and the core was placed horizontally and flooded by brine and IL mixtures at different scenarios to obtain the optimum concentration, slug size as well as initiation time. Eventually, all the above procedures were repeated in each experiment with fresh sand to maintain the same properties.

\section{Results and Discussion}

\subsection{Critical Micelle Concentration}

Surface tension (SFT) was considered to determine the Critical Micelle Concentration (CMC) of the displacing solutions at room conditions. The CMC is the concentration at which surfactant solutions surface tension could not be reduced further, as the concentration increased [18]. Moreover, ([EMIM][Ac]) has the capability to reduce the SFT regardless of solutions salinity [16]. As shown in Figure 2, a noticeable reduction in the SFT was observed, as the concentration of the IL increased from $0 \mathrm{ppm}$ to $1000 \mathrm{ppm}$. Any concentration greater than $1000 \mathrm{ppm}$ resulted in a slight increase in SFT values. It was observed that 1000 ppm of ([EMIM][Ac]) has the highest potential to reduce the SFT of the aqueous solution. So the concentration of $1000 \mathrm{ppm}$ was considered as the CMC of ([EMIM][Ac]). For alkali $\left(\mathrm{Na}_{3} \mathrm{CO}_{2}\right)$, as shown in Figure 3, 5000 ppm was considered as the CMC.

\section{2. $\mathrm{pH}$ and Conductivity Behaviors of Aqueous Solutions}

The $\mathrm{pH}$ values of ([EMIM][Ac]) and Weyburn brine mixtures were measured at $21.5^{\circ} \mathrm{C}$. It was found, in another study, that the $\mathrm{pH}$ values of the solutions increased with increasing ([EMIM][Ac]) concentration in the mixtures while the effect of temperature was marginal [19]. As expected, $\mathrm{pH}$ values decreased with increasing water content. Additionally, the alkali has the same effect on the $\mathrm{pH}$ as presented in Table 3.

Electrical conductivity of displacing phases was measured which increased

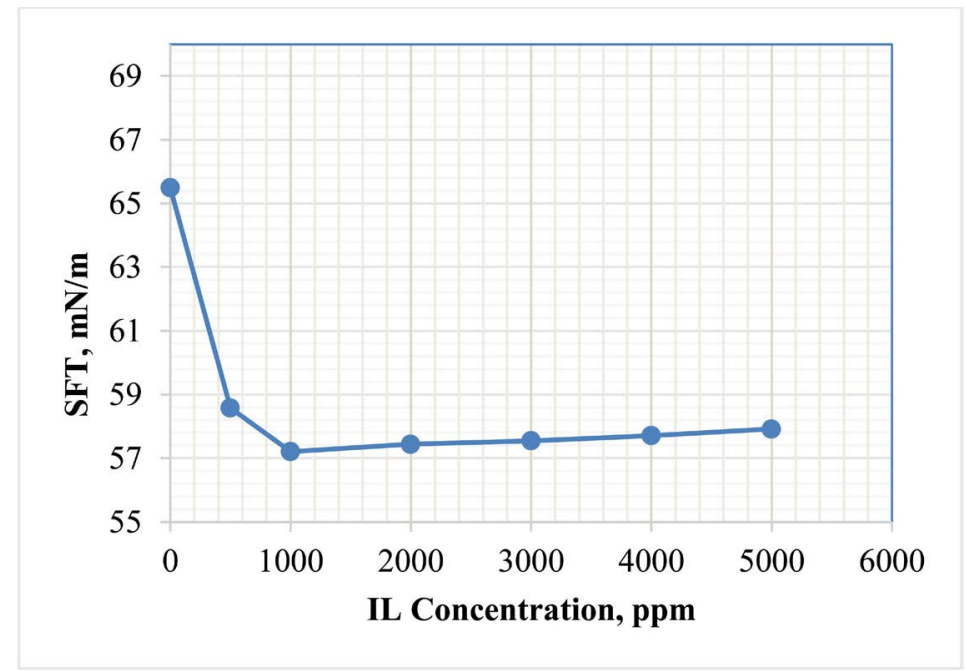

Figure 2. Effect of ([EMIM][Ac]) concentration on SFT of displacing phase. 


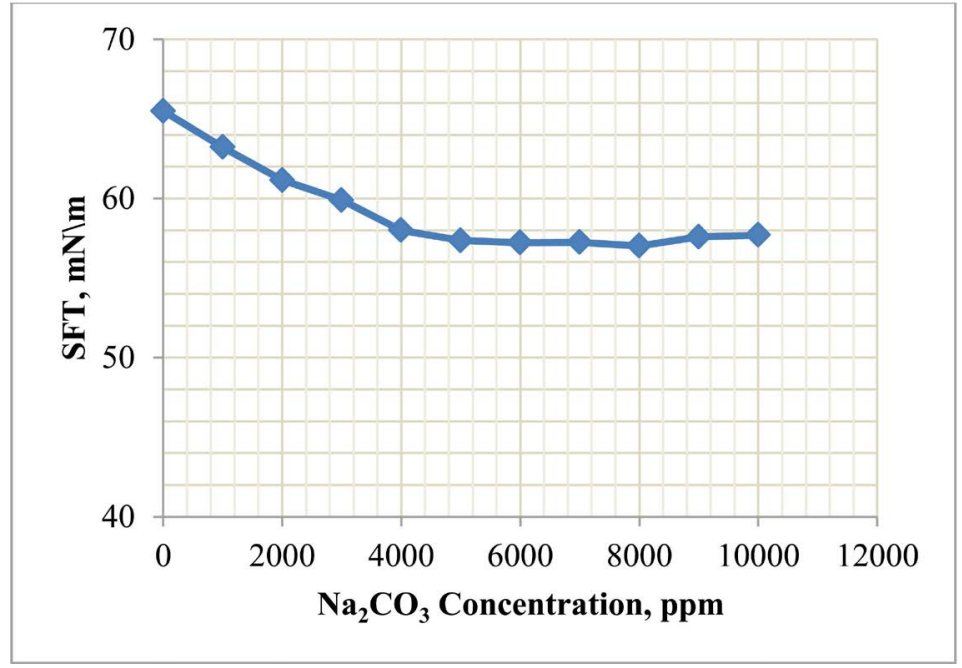

Figure 3. Effect of $\left(\mathrm{Na}_{2} \mathrm{CO}_{3}\right)$ concentration on SFT of displacing phase.

Table 3. pH and conductivity measurements of IL and Alkali + brine mixtures.

\begin{tabular}{cccc}
\hline Liquid sample & Mixture concentration (ppm) & Conductivity S $\backslash \mathrm{m}$ & $\mathrm{pH}$ \\
\hline Brine & - & 11.72 & 7.256 \\
$([\mathrm{EMIM}][\mathrm{Ac}])$ & 500 & 11.65 & 7.255 \\
& 1000 & 09.48 & 7.356 \\
& 2000 & 10.02 & 7.359 \\
& 3000 & 10.51 & 7.361 \\
& 4000 & 11.01 & 7.378 \\
$\left(\mathrm{Na}_{2} \mathrm{Co}_{3}\right)$ & 5000 & 11.23 & 7.396 \\
& 5000 & 10.56 & 7.346 \\
\hline
\end{tabular}

with increasing ([EMIM][Ac]) concentration. Similar to the CMC values that obtained from conductivity as function of tributylmethyl phosphonium dodecylsulfate concentration which was in good agreement with the CMC that attained from surface tension measurements [20]. The CMC point obtained from surface tension measurements for ([EMIM] [Ac] $)+$ brine solutions was in a great agreement with that obtained from conductivities values versus ([EMIM][Ac]) concentrations.

\subsection{Effect of ([EMIM][Ac]) Concentration on the RF}

After preparing the sand pack sample in each experiment, the rock properties were measured, as presented in Table 2. In order to obtain the optimum ([EMIM] [Ac]) concentration of displacing phase, three sand pack flooding experiments were performed with three different concentration (1000 ppm, 3000 ppm, and $5000 \mathrm{ppm}$ ) and compared with injecting brine alone into sand pack. The flooding process was divided into three stages. First, the sand pack was flooded for one pore volume by formation brine (as secondary recovery mode) followed by one pore volume of IL mixtures. Finally, the sand pack sample was flushed by brine for one pore volume. As shown in Figure 4, the produced oil 


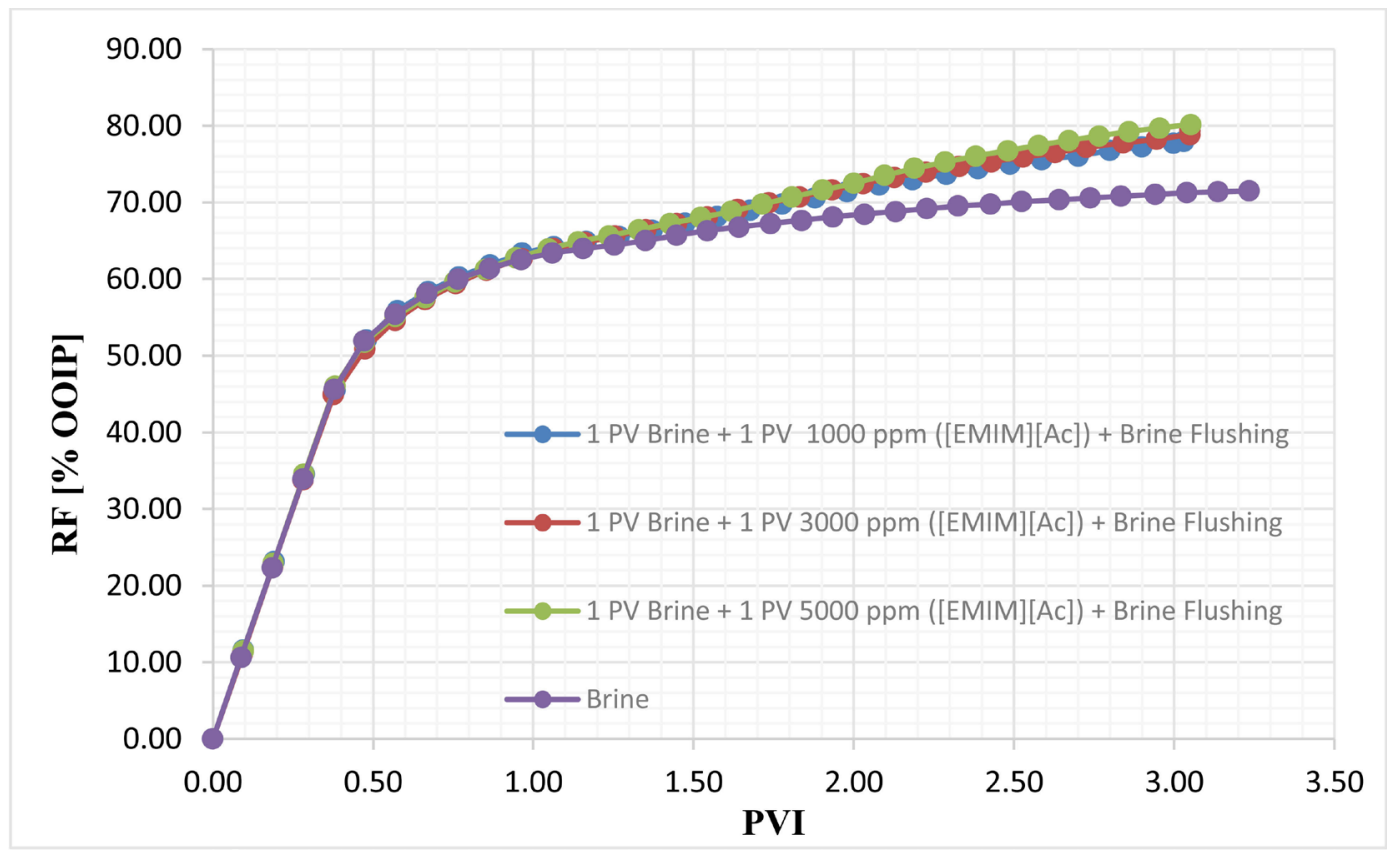

Figure 4. Effect of ([EMIM][Ac]) concentration on the RF in tertiary flooding.

was almost identical and the RF values are close to $(63 \% \pm 1 \%)$ at the end of the first stage. The increase in IL concentration from $1000 \mathrm{ppm}$ to $5000 \mathrm{ppm}$ increased the RF from $77 \%$ to $80.64 \%$ of original oil in place (OOIP) at end of flooding. Compared to using only water flooding which recovered about $71.17 \%$ of the oil in the sand pack sample, the addition of (1000 ppm, $3000 \mathrm{ppm}$, and $5000 \mathrm{ppm})([\mathrm{EMIM}][\mathrm{AC}])$ with the displacing fluid lead to an increase in the oil recovery by $6.57 \%$ OOIP, $7.37 \%$ OOIP, and $8.77 \%$ OOIP, respectively. Finally, as we can see in Figure 4, the increasing on ([EMIM][Ac]) concentration more than $1000 \mathrm{ppm}$ in the mixtures was not efficient to recover more oil economically. Also, the CMC point from SFT and conductivity values were obtained at $1000 \mathrm{ppm}([\mathrm{EMIM}][\mathrm{Ac}])+$ brine solution.

\subsection{Effect of ([EMIM][Ac]) Slug Size on the RF}

Three experiments were performed to select the optimum slug size (SS). In those experiments, the sand pack samples were initially flooded with $1.25 \mathrm{PV}$ of formation brine, followed by different SS (0.5, 1 and $2 \mathrm{PV}$ ) of $1000 \mathrm{ppm}$ ([EMIM] $[\mathrm{Ac}])$, and then the samples were flushed with formation brine. As shown in Figure 5, the total obtained RFs of injecting $0.5,1$, and 2 PV SS were $74.85 \%$ OOIP, $77.21 \%$ OOIP and 77.23\% OOIP, respectively. Regarding the RF results, it is obvious that $1 \mathrm{PV}$ of $1000 \mathrm{ppm}$ ([EMIM] [Ac]) is the optimum SS.

\subsection{Effect of ([EMIM][Ac]) Flooding Initiation Time on Improving Oil Recovery}

In order to obtain the appropriate initiation time of the chemical slug, the optimum concentration and slug size of ([EMIM][Ac]) were investigated at three different injection times, as shown in Figure 6. First, the sand pack was initially 


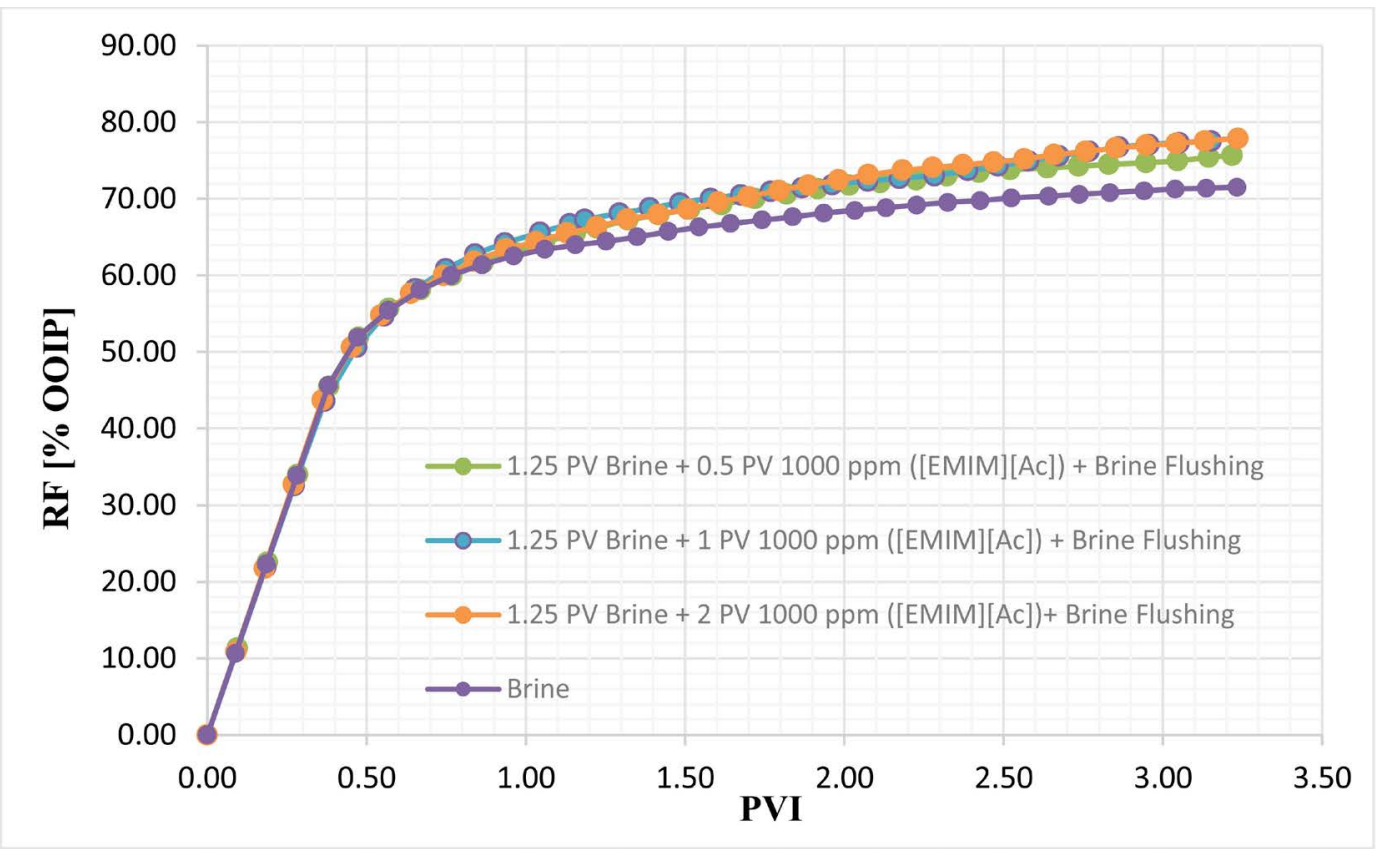

Figure 5. Effect of ([EMIM] [AC]) slug size on the recovery factor in tertiary recovery mode.

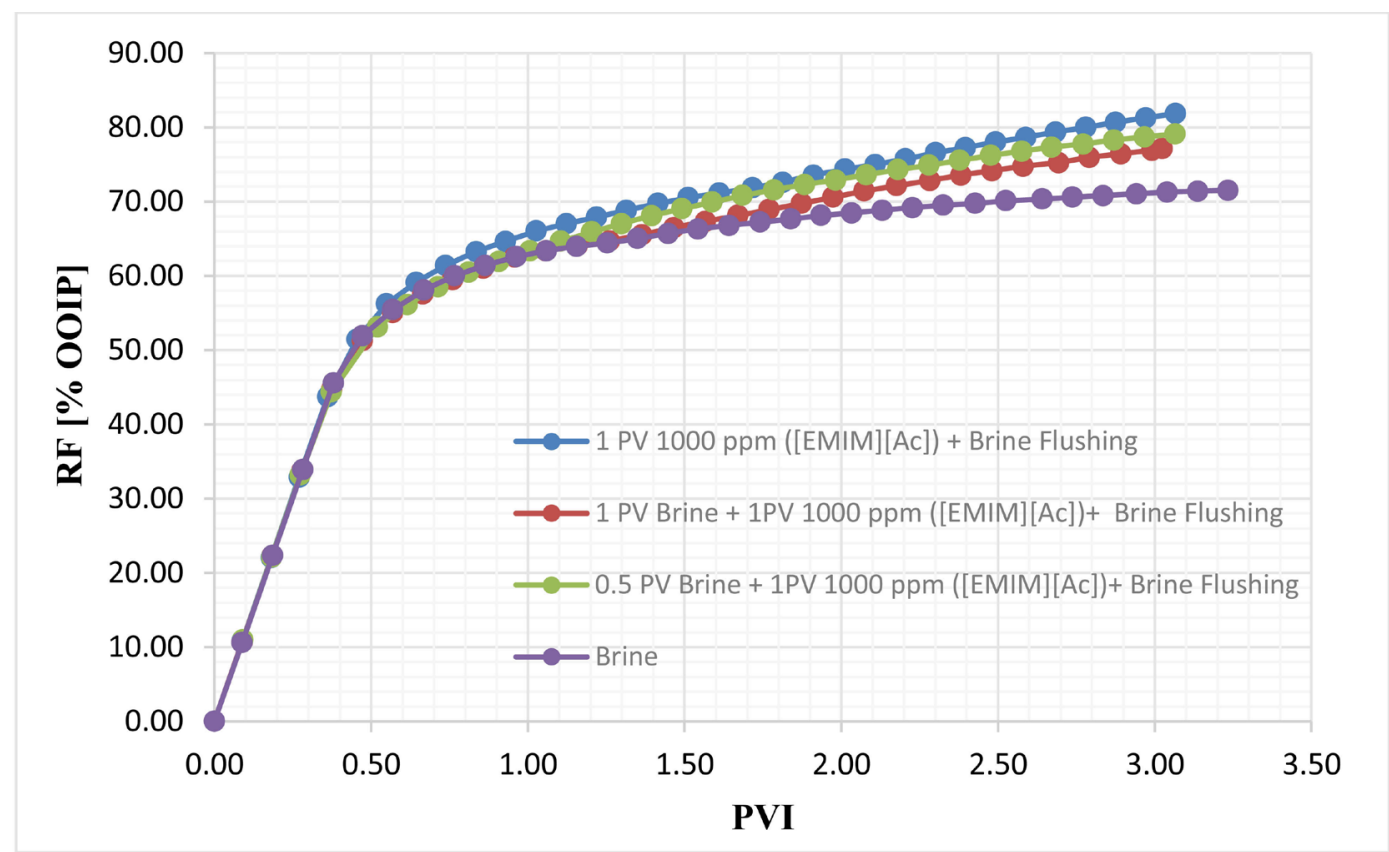

Figure 6. Effect of slug initiation time on the RF.

flooded with $1 \mathrm{PV}$ of $1000 \mathrm{ppm}$ ([EMIM][Ac]), and then it was flushed with 2 PVs of formation brine. The results showed that the RF increased from $71.17 \%$ OOIP of only brine flooding to $81.31 \%$ OOIP. Second, the injection time investigation occurred when the sand pack was flooded with $0.5 \mathrm{PV}$ formation brine; followed by $1 \mathrm{PV}$ of $1000 \mathrm{ppm}$ ([EMIM][Ac]), then finally, the sample was flushed with 1.5 PV of formation brine, as shown in Figure 5. The accumulative $\mathrm{RF}$ for this run was $79.01 \%$ OOIP, which is less efficient than that of starting the flooding with the chemical slug. The last examined injection time of the chemi- 
cal slug started with introducing $1 \mathrm{PV}$ of formation brine to the porous medium, followed by $1 \mathrm{PV}$ of $1000 \mathrm{ppm}$ ([EMIM][Ac]), and then flushed with $1 \mathrm{PV}$ of formation brine. The RF was just 76.95\% OOIP, which is less than the final RF of the two previous tests. In conclusion, It is obvious that the earlier the injection of the chemical the better the achieved RF.

\subsection{Effect of Continuous Injection ( $3 \mathrm{PV}$ ) of $1000 \mathrm{ppm}$ ([EMIM][Ac]) on the RF}

In this section, the efficiency of injection $3 \mathrm{PV}$ of $1000 \mathrm{ppm}$ on the RF was studied. As can be depicted from Figure 7 depicts the total RF (84.41\% OOIP) and it is noticeably better than that of injecting only Weyburn brine. Apart from the economics, the continuous flooding of the chemical mixture is also more efficient than chemical slug and injection.

\subsection{Effect of Alkalis/Ionic Liquid Slug on RF}

One of the upsides of injecting alkali is its ability to react with oil component in order to generate surfactants [21]. Before injection alkali/IL slug, the optimum concentration $(5000 \mathrm{ppm})$ of alkali $\left(\mathrm{Na}_{2} \mathrm{CO}_{3}\right)$ based on SFT measurements was obtained. Therefore, $1 \mathrm{PV}$ slug with $5000 \mathrm{ppm} \mathrm{Na}_{2} \mathrm{CO}_{3}$ was introduced from the beginning of the flooding process and followed by 2 PVs of Weyburn brine to flush the core sample. In comparison to the results of injection brine alone, an extra $4 \%$ OOIP was recovered due to the potential of the added alkali. In addition, combing IL with alkali resulted in much better RF than injection just alkali. When $1000 \mathrm{ppm}$ of ([EMIM][Ac]) was added to $5000 \mathrm{ppm}\left(\mathrm{Na}_{2} \mathrm{CO}_{3}\right)+$ Weyburn brine slug, the RF was improved from $77.52 \%$ OOIP of injecting alkali + Weyburn brine slug alone to $83.95 \%$ OOIP, as shown in Figure 8.

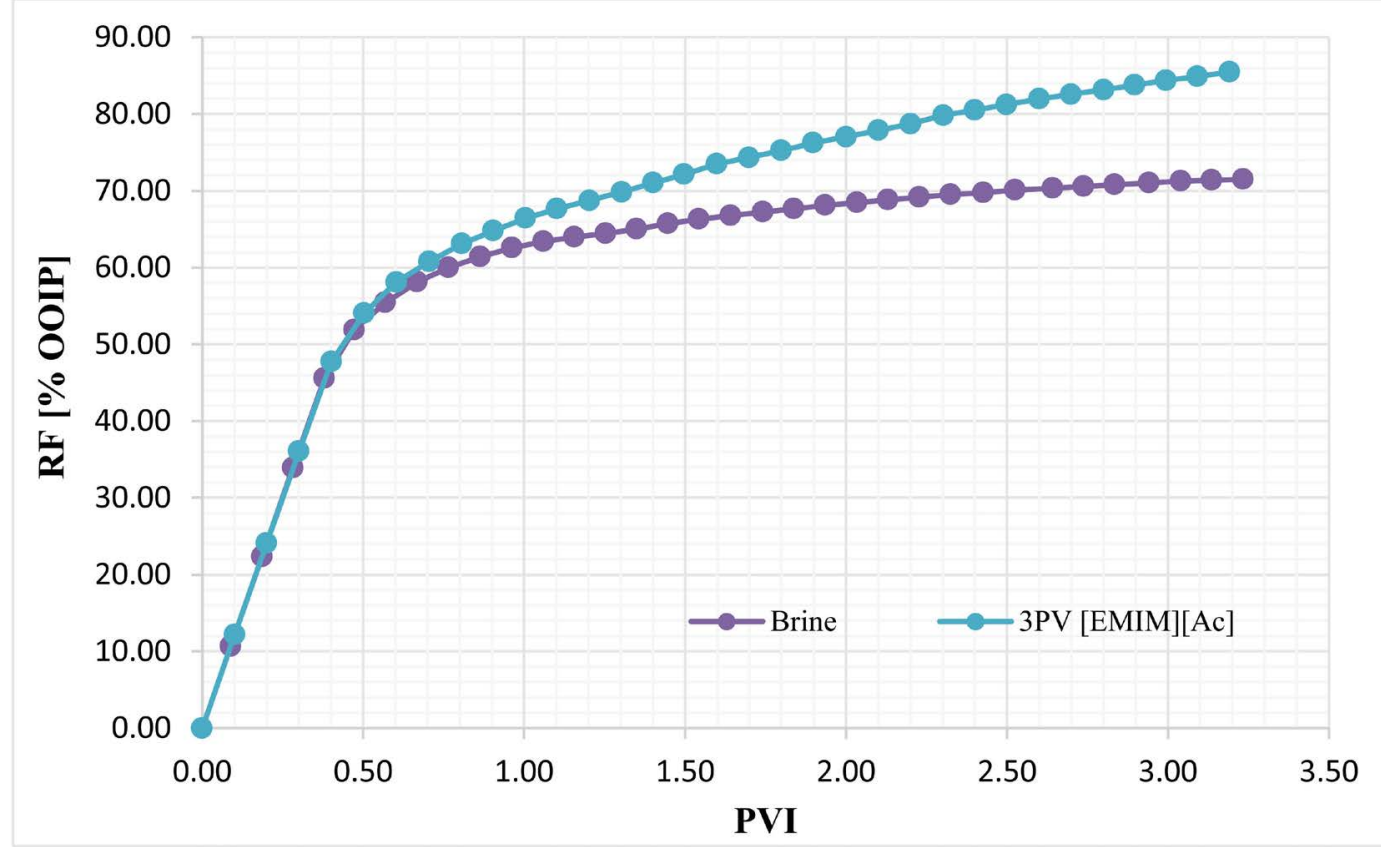

Figure 7. Effect of ([EMIM][Ac]) on the recovery factor in different recovery mode. 


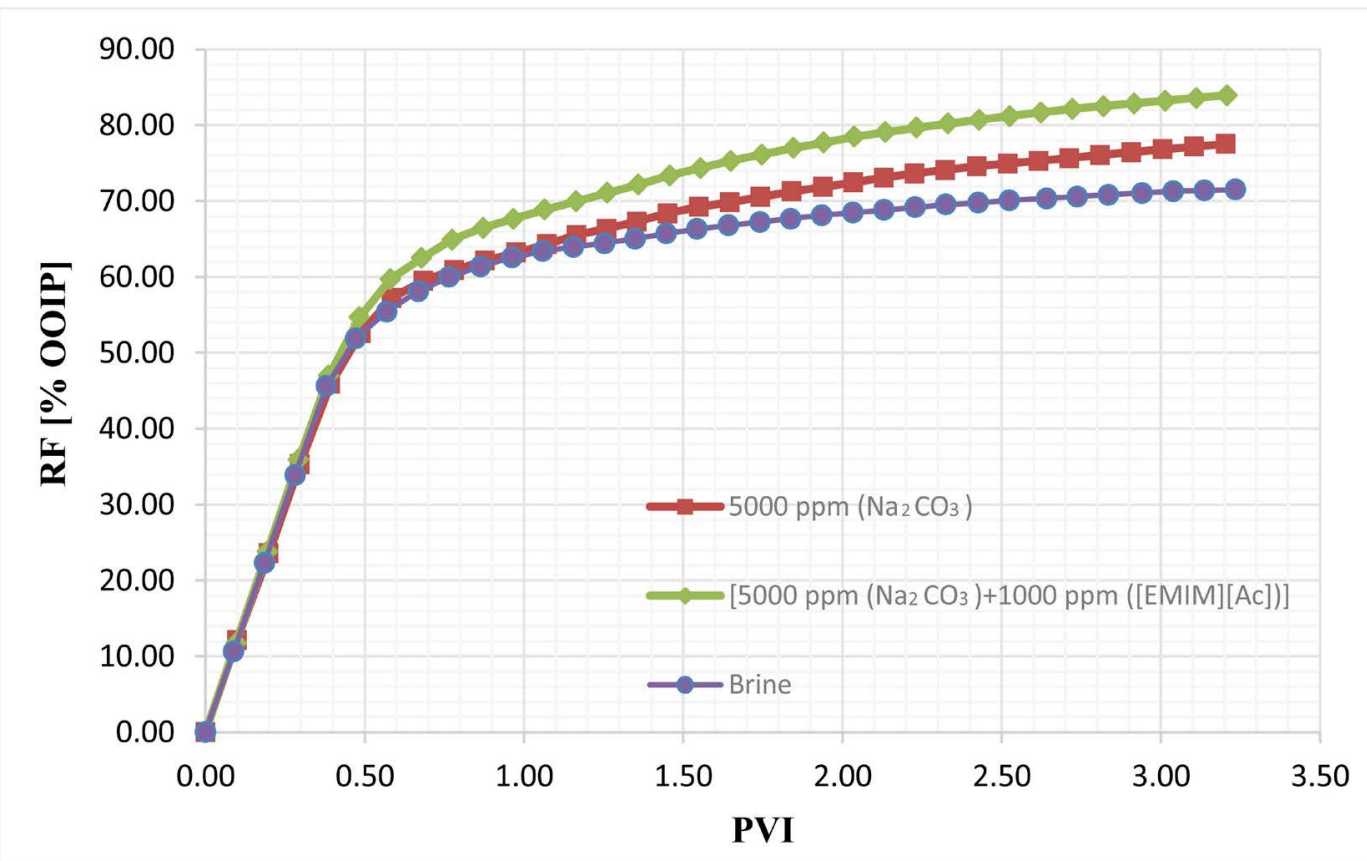

Figure 8. Effect of $\left(\mathrm{Na}_{2} \mathrm{CO}_{3}\right)$ on the RF in secondary recovery mode.

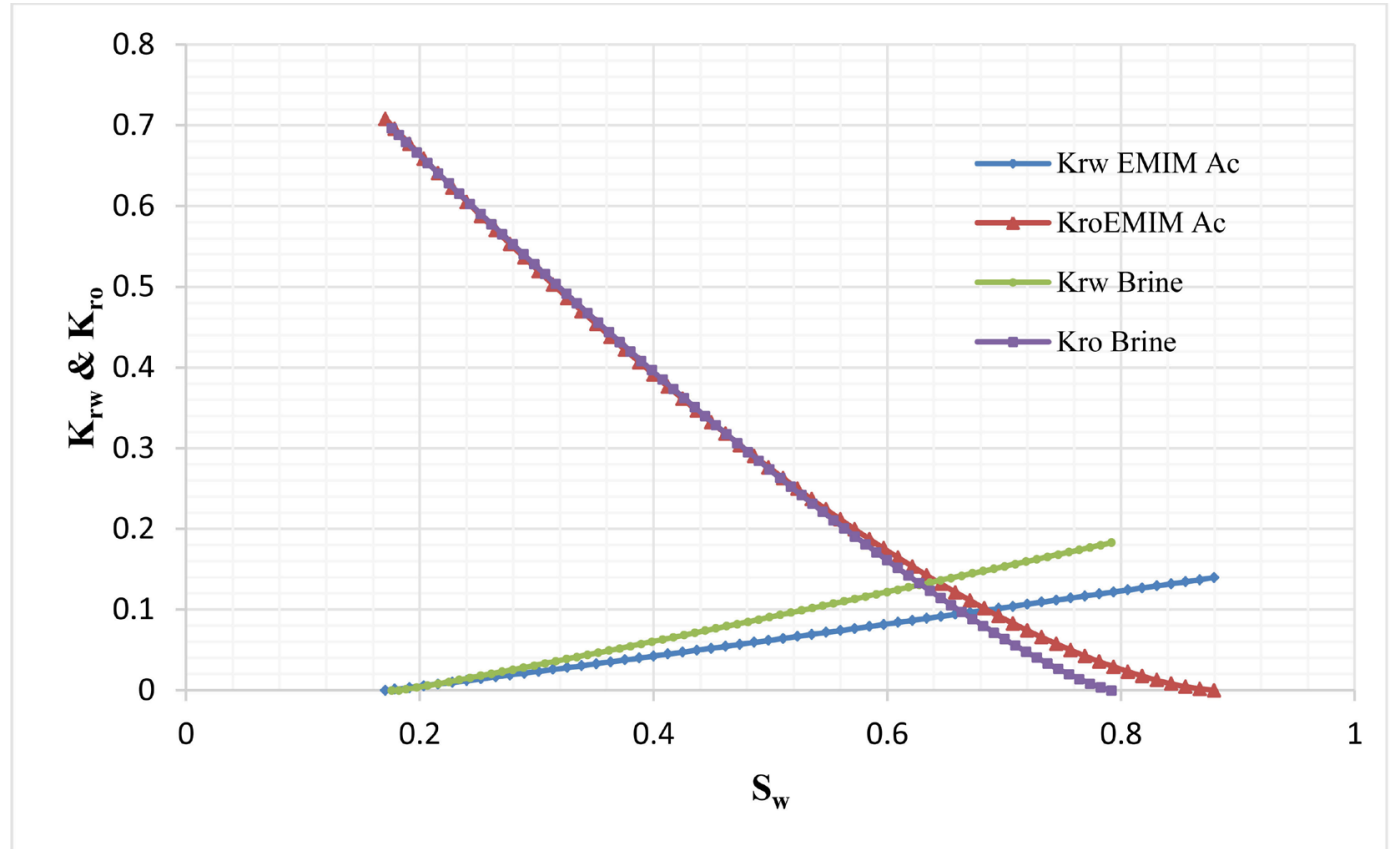

Figure 9. Relative permeability curves of continuous flooding with brine and [EMIM] [Ac] solution.

\subsection{Relative Permeability Curves}

To investigate the effect of ILs on wettability alteration, relative permeability $\left(\mathrm{k}_{\mathrm{ro}}\right.$ $\& \mathrm{k}_{\mathrm{rw}}$ ) curves have been calculated and plotted for two flooding experiments (IL + Weyburn brine flooding and Weyburn brine flooding only) under the same conditions. So, $\mathrm{k}_{\mathrm{ro}}$ and $\mathrm{k}_{\mathrm{rw}}$ of $1000 \mathrm{ppm}$ ([EMIM][Ac]) + Weyburn brine and just Weyburn brine were calculated using step by step graphical technique that was explained by Jones and Roszelle (1978) [22]. As shown in Figure 9, the rock wa- 
ter wetness increases and the residual oil saturation decreases for IL slug flooding comparing with brine flooding. These outcomes confirm the enhancement in the RF results in our study.

\section{Conclusion}

This paper studied the application of ([EMIM][Ac]) as an alternative surfactant to increase the medium Weyburn recovery factor from unconsolidated Ottawa sand pack at room conditions. The work began by measuring the surface tension of the ([EMIM][Ac]) IL mixed with brine at different concentrations. The ([EMIM][Ac]) was able to reduce the SFT of the displacing fluid from 65.4 $\mathrm{mN} / \mathrm{m}$ to $57.2 \mathrm{mN} / \mathrm{m}$ and the CMC point was investigated when the ([EMIM] [Ac]) concentration was $1000 \mathrm{ppm}$ in the displacing fluid, which was the minimum reduction on SFT and in a good agreement with conductivities values versus ([EMIM][Ac]) concentrations. A series of flooding experiments on Ottawa sand pack samples were done to demonstrate the effect of ([EMIM][Ac]) ionic liquid at different conditions, (concentration, slug size, and initiation time), on oil recovery. From the flooding results, all showed an increase of the recovery factor. Recovery factor was possible to reach up to $84 \%$ of OOIP when $1000 \mathrm{ppm}$ $([\mathrm{EMIM}][\mathrm{Ac}])+$ brine mixture injected into sand pack sample as secondary recovery mode either as a one pore volume the flushed by brine or a continuous ionic solution flooding. Moreover, the recovery factor was higher when IL combined with alkali (AIL) flooded at the same condition and selected mode, secondary mode flushed by brine. The relative permeability curves of continuous brine flooding and 1000 ppm ([EMIM][Ac]) + brine flooding indicated wettability alteration toward a slight increase in rock water wet characteristics. The ([EMIM][Ac]) ionic liquid increases the viscosity of the ([EMIM][Ac]) + brine mixtures, which is one of the mechanisms increasing the recovery factor.

\section{References}

[1] Nilsson, S., Lohne, A. and Veggeland, K. (1997) Effect of Polymer on Surfactant Flooding of Oil Reservoirs. Colloids and Surfaces A: Physicochemical and Engineering Aspects, 127, 241-247. https://doi.org/10.1016/S0927-7757(97)00140-4

[2] Speight, J.G. (2009) Enhanced Recovery Methods for Heavy Oil and Tar Sands. Gulf Publishing Company, Houston.

[3] Han, D., Yang, C., Zhang, Z., Lou, Z. and Chang, Y. (1999) Recent Development of Enhanced Oil Recovery in China. Journal of Petroleum Science and Engineering, 22, 181-188. https://doi.org/10.1016/S0920-4105(98)00067-9

[4] Nagarajan, R. and Harold, M.P. (1982) Surfactant-Polymer Interactions in Tertiary Oil Recovery. Solution Behavior of Surfactants, 2, 1391-1413. https://doi.org/10.1007/978-1-4613-3494-1_44

[5] Healy, R.N. and Reed, R.L. (1974) Physsicochemical Aspects of Microemulsion Flooding. Society of Petroleum Engineers Journal, 14, 491-501. https://doi.org/10.2118/4583-PA

[6] Jamaloei, B.Y. (2009) Insight into the Chemistry of Surfactant-Based Enhanced Oil Recovery Processes. Recent Patents on Chemical Engineering, 2, 1-10. https://doi.org/10.2174/2211334710902010001

[7] Lake, L.W. and Venuto, P.B. (1990) A Niche for Enhanced Oil Recovery in the 
1990s. Oil \& Gas Journal, 88, 62-67.

[8] Xiao, Y. and Malhotra, S.V. (2005) Friedel-Crafts Acylation Reactions in Pyridinium Based Ionic Liquids. Journal of Organometallic Chemistry, 690, 3609-3613. https://doi.org/10.1016/j.jorganchem.2005.04.047

[9] Lemos, R.C., da Silva, E.B., dos Santos, A., Guimaraes, R.C., Ferreira, B.M., Guarnieri, R.A. and Fortuny, M. (2010) Demulsification of Water-in-Crude Oil Emulsions Using Ionic Liquids and Microwave Irradiation. Energy \& Fuels, 24, 44394444. https://doi.org/10.1021/ef100425v

[10] Dharaskar Swapnil, A. (2012) Ionic Liquids (A Review): The Green Solvents for Petroleum and Hydrocarbon Industries. Research Journal of Chemical Sciences, 2, 80-85.

[11] Hogshead, C.G., Manias, E., Williams, P., Lupinsky, A. and Painter, P. (2010) Studies of Bitumen-Silica and Oil-Silica Interactions in Ionic Liquids. Energy \& Fuels, 25, 293-299. https://doi.org/10.1021/ef101404k

[12] Painter, P., Williams, P. and Lupinsky, A. (2010) Recovery of Bitumen from Utah Tar Sands Using Ionic Liquids. Energy \& Fuels, 24, 5081-5088. https://doi.org/10.1021/ef100765u

[13] Williams, P., Lupinsky, A. and Painter, P. (2010) Recovery of Bitumen from LowGrade Oil Sands Using Ionic Liquids. Energy \& Fuels, 24, 2172-2173.

https://doi.org/10.1021/ef901384s

[14] Hezave, A.Z., Dorostkar, S., Ayatollahi, S., Nabipour, M. and Hemmateenejad, B. (2013) Investigating the Effect of Ionic Liquid (1-Dodecyl-3-Methylimidazolium Chloride $\left.\left(\left[\mathrm{C}_{12} \mathrm{mim}\right][\mathrm{Cl}]\right)\right)$ on the Water/Oil Interfacial Tension as a Novel Surfactant. Colloids and Surfaces A: Physicochemical and Engineering Aspects, 421, 63-71. https://doi.org/10.1016/j.colsurfa.2012.12.008

[15] Fathi, S.J., Austad, T. and Strand, S. (2011) Water-Based Enhanced Oil Recovery (EOR) by "Smart Water": Optimal Ionic Composition for EOR in Carbonates. Energy \& Fuels, 25, 5173-5179. https://doi.org/10.1021/ef201019k

[16] Tunnish, A., Shirif, E. and Henni, A. (2016) Enhanced Heavy Oil Recovery Using 1-Ethyl-3-Methyl-Imidazolium Acetate. The Canadian Journal of Chemical Engineering, 95, 871-879.

[17] Pereira, J.F., Costa, R., Foios, N. and Coutinho, J.A. (2014) Ionic Liquid Enhanced Oil Recovery in Sand-Pack Columns. Fuel, 134, 196-200. https://doi.org/10.1016/j.fuel.2014.05.055

[18] Kopczynska, A. (2007) Polymeric Surfaces and Their True Surface Tension in Solids and Melts. Journal of Materials Education, 29, 325.

[19] Ober, C.A. and Gupta, R.B. (2012) pH Control of Ionic Liquids with Carbon Dioxide and Water: 1-Ethyl-3-methylimidazolium Acetate. Industrial \& Engineering Chemistry Research, 51, 2524-2530. https://doi.org/10.1021/ie201529d

[20] Rodríguez-Escontrela, I., Rodríguez-Palmeiro, I., Rodríguez, O., Arce, A. and Soto, A. (2016) Characterization and Phase Behavior of the Surfactant Ionic Liquid Tributylmethylphosphonium Dodecylsulfate for Enhanced Oil Recovery. Fluid Phase Equilibria, 417, 87-95. https://doi.org/10.1016/j.fluid.2016.02.021

[21] Xu, Z., Shaw, A., Qiao, W. and Li, Z. (2012) Branched Chains of Aryl Alkyl Surfactants Effects on the Interfacial Tension between Crude Oil/Surfactant-Alkaline Systems. Energy Sources, Part A: Recovery, Utilization, and Environmental Effects, 34, 1723-1730. https://doi.org/10.1080/15567036.2010.490822

[22] Jones, S.C. and Roszelle, W.O. (1978) Graphical Techniques for Determining Relative Permeability from Displacement Experiments. Journal of Petroleum Technology, 30, 807-817. 


\section{Nomenclature}

$\mathrm{C}_{([\mathrm{EMIM}][\mathrm{Ac}])}([\mathrm{EMIM}][\mathrm{Ac}])$ concentration

$\mathrm{C}_{(\mathrm{Na} 2 \mathrm{CO} 3)}\left(\mathrm{Na}_{2} \mathrm{Co}_{3}\right)$ concentration

ppm parts per million

$\mathrm{PV} \quad$ pore volume

K absolute permeability

$\mathrm{k}_{\mathrm{ro}} \quad$ oil relative permeability

$\mathrm{k}_{\mathrm{rw}} \quad$ water relative permeability

$\mathrm{S}_{\mathrm{wi}} \quad$ initial water saturation

$\mathrm{S}_{\mathrm{oi}} \quad$ initial oil saturation

Greek Letters

$\begin{array}{ll}\varnothing & \text { Porosity } \\ \rho & \text { Density } \\ \mu & \text { Viscosity }\end{array}$

$\mu \quad$ Viscosity

Submit or recommend next manuscript to SCIRP and we will provide best service for you:

Accepting pre-submission inquiries through Email, Facebook, LinkedIn, Twitter, etc. A wide selection of journals (inclusive of 9 subjects, more than 200 journals)

Providing 24-hour high-quality service

User-friendly online submission system

Fair and swift peer-review system

Efficient typesetting and proofreading procedure

Display of the result of downloads and visits, as well as the number of cited articles Maximum dissemination of your research work

Submit your manuscript at: http://papersubmission.scirp.org/

Or contact aces@scirp.org 